\title{
Beyond Professionalism: Can a Good Engineer Make a Good Political Leader?
}

\author{
Ugochukwu C. Okonkwo \\ Department of Mechanical Engineering, Nnamdi Azikiwe University, Awka \\ Tel: +2348037512208_ E-mail: ugocoons@yahoo.com \\ Accepted: March 05, 2013 Published: May 01, 2013 \\ Doi:10.5296/ijld.v3i2.3615 URL: http://dx.doi.org/10.5296/ijld.v3i2.3615
}

\begin{abstract}
There has been an established myth of stereotype traits which good political leaders must possess, but which unfortunately as interpreted by many, are generally lacking in a typical engineer, making him unfit for such positions. In this paper, reflections and justifications why engineers are fit for leadership positions were made. It discusses some of the engineering potentials like creativity, drive for implementation of concepts, the strength behind an introverted nature, and social responsibility and how it can be adapted for leadership position. It compares and contrasts engineers and scientists as far as leadership are concerned. The summary of the findings is that a good engineer can make a good political Leader.
\end{abstract}

Keywords: Engineer, Professionalism, Political leader, Potential

\section{Introduction}

The question which the title of this article raises is not a technical question that an engineer can claim expertise in handling. It is a sociological question and by training and background, engineering is far from sociology. However, it will be answered by an engineer because it is personalized, requiring his self discovery, analysis and appraisal. The near absence of engineers in politics started with the early engineers. They distanced themselves from politics because they consider their job too time consuming to accommodate the hustle and bustle of politics. Unfortunately, they forgot that if one has technology but lacks the political power to sustain it, his technology will be taken away from him.

This alienation not only in politics but other societal interactions contributed in creating an image problem for engineers, causing most people think of engineering as being a job concerned only with objects and gadgets rather than people. Ironically, engineers who have been wrongly labeled by the society are in their quiet enclave finding solutions to societal problems. Engineers themselves are not helping matters to correct this notion and it seemed as if they have adopted this image. To buttress this fact, engineering courses and curricula, most times, simply assume inadvertently that political power and leadership are reserved for certain people. Such people have the job of taken decisions on government policies and defining the trend of events, while Engineers are only there to help them to succeed. Hence, a question to be answered in an engineering course may begin with "Assume you are employed by a government parastatal ...", "Assume you have been contracted a government project...". Framing question only in this manner assumes that a student engineer needs not ask such prior question as: Should this be the trend that must be followed? Can I not be the political leader awarding the project? Must this always be the boundary in which the practice of my hard earned knowledge and skill revolve? Can my skill not be utilized in taking decisions on the 
formulated alternative policies that will lead to the contract award for the project? This pattern (mindset) has been carried from generation to generation because as one enters a profession, he simply embraces the existing institutional patterns and leadership roles the profession offers. Hence, there is a need to re-evaluate and change this mindset.

\section{Opinions against Engineer Leadership Potentials}

Literature abound characterizing the personality of Engineers. Saviour ${ }^{[1]}$ opined that several engineers have substantially the same traits that a stereotype personality has evolved depicting them. Unfortunately, from literature, the stereotype personality traits of engineers are quite opposite to the traits which a good political leader should possess, and so engineers are not considered for leadership positions in politics. Hence, literature relating engineers with political leadership capabilities are few while the literature out rightly supporting them as possessing good political leadership qualities are very scanty and shallow. Jim $^{[2]}$ asserts that the major obstacle preventing a good number of engineers from being leaders is their high propensity to focus on details, rather than the overall, broad picture. He pointed out that leaders must have a clear understanding of what it takes to accomplish the overall objective effectively. Some writers have also observed that engineers are reluctant to lead; in that line, Hawley ${ }^{[3]}$ said that some engineers make excellent managers but never want to be leaders. Also, Pinto ${ }^{[4]}$ accuses Engineers from running away from this position by saying that they do not want to be leaders because they recognize that leadership involves many things beyond technical details, besides, they are weak communicators. In line with the latter, Kolla ${ }^{[5]}$ mocked Engineers by saying that an engineer is the kind of person who when you give him an applied kind of problem will go about in a corner and work it out for you, but do not ask him how he got it, do not expect him to articulate himself, he is such a faceless anonymous character. In other words, he has a lower self image and confidence. Also, Meyers and Briggs in their personality's trait, rated most engineers as introverted and introverted people are not normally good in public speaking. Viewed in another unfavourable manner, Saviour ${ }^{[1]}$ opined that engineers are dogmatic because they are attached to structures which may lead to authoritarian approach in solving problems. It was this sort of reaction that Vinto ${ }^{[6]}$ was commenting upon when he said that engineers can be insensitive to the feelings of others because they usually interact with nature and not with humans.

There is a tendency to undervalue people with technical skills (engineers). In his book ${ }^{[7]}$, Fred Brooks says that managers (leaders) think of senior people as too valuable for technical tasks (engineering). Beyond that, Revelle ${ }^{[8]}$ opined that the personalities, motivations and orientations of engineers and leaders are each foreign to the other. He summarized by saying that while the engineer seeks power over nature, the politician seeks power over men. You can see from the above that engineers are left out of the equation when leadership is involved. To buttress this fact, President J. F. Kennedy once said that whenever you engineers invent a new technology, we politicians have to make a new political invention to deal with it. Batchelder ${ }^{[9]}$ in his own submission said that the Engineer who essentially deals with a direct creation, usually finds it difficult with indirect work that a Leader is mainly involved in. As a leader, you often do not directly build something yourself, you are enabling someone else to build. You are setting direction and coordinating groups to achieve a desired objective eventually. Engineers do not really appreciate the subtler effect by setting this direction and coordinating these groups, because they were thought to value direct creation. In another development, it is always said that to be a good leader you must be a good follower. Batchelder ${ }^{[9]}$ went further to say that Engineers are solo creators. They are used to doing things themselves. It can be hard for them to ask for help because they do not want to be seen as incapable or because they do not want to bother others. 
Most of the authors that wrote on making engineers fit for leadership position always have one solution, that is the expansion of the engineering educational curriculum to involve enough culture and humanities that will equip them for leadership roles or attendance to conferences, seminars or workshops specifically designed for that purpose. Saviour ${ }^{[1]}$ went further by finding that there are strengths in those traits that may not be considered favourable for leadership roles. For instance, he said that engineers can be dogmatic which is not good for leadership but that trait that made them to be dogmatic can also make them to be determined and focused. In other words 'dogmatism' equals 'determined and focused'. This article, just like Saviour ${ }^{[1]}$ will deal more on the strengths behind the apparently unfavourable personality traits of engineers for leadership position.

\section{Engagement of Engineers in Leadership Roles}

The lack of ability among engineers and other technical professionals to engage in political reflection is by now much more than a small failure in education; it threatens to become a great tragedy ${ }^{[10]}$. Many people will agree that engineering education is the best training to nurture thinking and the thought process ${ }^{[11]}$. Therefore, how do we tune our engineering education to produce the best cognitive thinking that is required in leadership position. How do we command the ability to think and yet feel, to judge and yet perceive, to make decision in both regimented and chaotic situations and to be extroverted and introverted at the same time to achieve the best result.

Many of the most significant ways in which old forms of power are reproduced and new ones are created are reflected in the technologies we use. To a great extent, the possibilities of social and political life are defined by technological opportunities and constraints. In other words whether we are to have a good society or a bad one is powerfully influenced by the technologies we develop and put to use, just the same way leadership has some influence on the society. Hence, the products of engineers are not only for solving technical problems but extend to social, economic and political life in the society ${ }^{[12][13]}$. To that extent therefore, political leadership and engineering share a convergence of goals, they have a common project which is making things that will endure. It might even be argued that they share some of the same criteria of evaluation: a concern for the appropriate furnishings of the good life ${ }^{[14]}$.

Momah $^{[14]}$ while relating engineering and our economy and how we must reflect constantly on it said that technology is the language of the future and science is its grammar and so, only those who can speak the language will be relevant in the 21 st century and those who are not, will be swept into the dust bin of history. In other words, if a good knowledge of engineering is relevant for us to exist at this time and age, it implies that for one to effectively pilot the affairs as a leader, this attribute is indispensable. Indeed, for accelerated sustainable technological development in any society, such a society must think like an engineer, talk from engineering experience, trust engineering products and create opportunities for engineers to be placed in leadership positions of that society. This placement cannot be done if those that will be placed did not structure themselves well. Hence, Engineers should re-organize and inculcate a new confidence in themselves, identify and comfortably take their position. This is indeed a new beginning and a new hope for a change that is long overdue.

The time is ripe for engineers to define their priorities as far as political leadership is concerned. Engineers need to move beyond the entities as given by Billington ${ }^{[15]}$ who categorized engineering entities as machines, structures, networks, and processes. Moving beyond these entities will help in preservation and proper utilization of the obvious engineering 
entities. They must be willing to acknowledge the significance and importance of public service and its place in society, stretching their traditional comfort zone of being leaders only in their professions. Accepting the challenge of bringing true leadership spiced with engineering traits well beyond the roles accepted in the past. Indeed, Engineers should recognize that their leadership will facilitate sustainable technology and development.

\section{Integrating System Efficiency in Political Leadership}

Engineers are experienced at enhancing cost effectiveness and system efficiency. They perhaps more than any other professionals, have the potential to cut away the bureaucratic tape or bottleneck that is the bane of political process. Politics desperately need new blood and novel thought processes to solve problems from a systems perspective, and to simply get things done. Engineers can capitalize on this opportunity, much as they do when involved in new system development. Their mindset has been focused to define a problem, identify alternatives and conflicting phenomena, carry out a tradeoff analysis and soon invent a process to reach to an optimized solution. This rational systematic way can effectively be extended to the political platform.

The engineer possesses the technical knowhow on how to tackle technological policies that political leaders encounter regularly. In fact, as pointed out by Loui ${ }^{[16]}$, this policy is so important to be left to career bureaucrats much less to politicians who are swayed by well heeled campaign contributions, who are counted by single-issue lobbyists and who are motivated primarily by a desire to be re-elected. Engineers have two excellent qualifications to adapt this system efficiency to political leadership positions. First, they have quantitative sense in numbers and they are good problem solvers. As leaders, Engineers can invoke their quantitative sense in solving social problems, not necessarily through routine calculations that accountants, scientists or even economists can do, but using the intuitive judgment that their profession has equipped them with to tackle leadership problems.

\section{Engineers and Scientists Leadership Propensities}

An aerospace Engineer, Theodore Von Karman once quoted that the Scientists explain that which exists while the Engineer creates that which never was. It is important to note that an Engineer function is distinct from that of a Scientist in our society. The Scientist always seeks out laws of the physical universe as well as the understanding of why they operate as they do. Colhoun $^{[17]}$ opined that the scientist looks for facts and for correlations between facts. But in the final analysis he is concerned with general laws and with general situations more than he is with specifics. When the scientist gets everything into one equation, then he has reached the climax of his activity because from this single equation he can deduce everything that he wants to know about why things are the way they are. Beyond the understanding of why, just for the sake of knowing, the Engineer goes further from where the Scientist stops to determine how a given objective can be achieved armed with the scientific knowledge. What actually sets Engineers apart from Scientists is their drive to solve practical problems and this active problem solving orientation is what is needed by the leader to address national social problems. The Engineer analyzes a particular need at a particular time within a particular set of conditions and he arrives at a particular solution to fill that need. In other words, the engineer shows how the timeless knowledge of science can be put to work in a given situation to meet a specific need at a specific time. ${ }^{[18]}$ 
The above attribute of engineering is very important in leadership. A leader that ends up in the formulation of beautiful policies without any form of implementation is obviously a bad leader. A leader that will not follow through the implementation of his policies cannot be classified as a good leader. However, a leader that follows through, weathering all challenges along the line and ensuring that the formulated specific policies are accomplished to meet needs of the society can of cause be said to be a good leader. It is indeed a thing of joy that Engineers fall into this category by training. In some developing countries like Nigeria, the leadership problem is not in the formulation of beautiful policies that will alleviate the suffering of the people, but the problem is in full implementation of those policies. In this regard therefore, Engineers can be said to have an edge over Scientists as far as leadership is concerned.

\section{The Introverted Traits of Engineers}

Engineers are generally categorized as introverts who are always considered to be passive or shy and so are not qualified for leadership position. The natural leader is often associated with the extrovert trait because of the misconception that a leader should always be at the center of communication, draw attention to himself and generally be very active. Actually, engineers may appear passive, but what they are doing is just to wait to speak until they have fully considered a matter thoroughly. They listen, observe, think and analyze a problem before acting, unlike an extrovert that will often take a hasty decision. In fact, if there is any time that a leader is required to show introverted trait, it is at this time. This is because in today's society in which democracy reigns, the followers need more freedom and want their ideas to be given a fair hearing and considered properly. An Engineer Leader, who is generally considered an introvert is the type of leader that will give others the opportunity to exercise their knowledge on an issue. They will definitely gain respect from their followers because they do not crave for lime light and do not usurp to themselves any credit that should have been given to other people.

The introverts believe in doing than in claiming, they like their achievements to speak for them. Indeed, the introverts are action oriented people, they are silent winners. Although the extrovert makes the first impression, but at the long run, the strength of the introvert exceeds the initial impression created by the extrovert. Extroverts are prone to changing their values as per situations and they are less trustworthy. Indeed, the introvert nature of an engineer will help him to accomplish more as a leader in real terms and not in propaganda.

\section{Social Responsibility of an Engineer}

A good leader is always conscious of his conduct because of the social responsibility which his position has placed him. This consciousness of course cannot be developed overnight. This gives an Engineer an advantage over others because it is already part of him. Engineers by training have been formed to place public safety and interest of the society ahead of all other considerations and obligations. In this line engineers take into account the consequences of their actions and inactions as well as the impact of their work on society and the citizenry. Engineers have fundamental canons and high ethical standards. The summary of which is to hold paramount the safety, health and welfare of the public in the performance of their professional duties ${ }^{[19]}$. They are in a better position to think about the interaction of their technology in the society since they know the technology at the most intimate level and are aware of its risks and limits as well as its benefits. 
The fact that Engineers are often employees in large organizations and ordinarily are supposed to implement the goals of their employers and clients, cannot be denied. In line with the above, Florman $^{[20]}$ argues that Engineers do not have the responsibility, much less the right, to establish goals for society and therefore they lack the decision making autonomy and power to take independent decisions in their profession. While the argument raised by Florman cannot be glossed over as entirely false, engineers have not taken Florman argument and similar arguments in that line as a subterfuge for inaction. It is worthy to state here that Engineers are not entirely left to the mercy of their employers. There are engineering professional societies to protect engineers that will blow the whistle on illegality or wrong-doing that will endanger the society. By the same token, engineers have a penchant for speaking plainly which will cause the followers to repose their trust and confidence in them.

From the foregoing, engineering profession is a profession that is always conscious of the impact of its products to the society. So Engineers always apply factors of safety in their design. A good engineer can be a good leader; at least the consciousness of being responsible to the society is part of him by training and he no longer needs to start learning it but to adapt it in his leadership roles. He can also adapt the knowledge of the factor of safety he has learnt in technical matters in his decision making process for the overall benefit of the society. Finally, the possession of a professional working framework as an engineer upon which high ethical standards are embedded offers him an indispensible tool for good leadership.

\section{Engineers Creativity and Leadership}

Creativity is the lifeblood for effective leadership. It is a journey in which the leader searches continually for concepts that are superior to the ones currently in use. Creativity can he improved by training. In support of this, Perkins ${ }^{[21]}$ confirmed that creativity arises naturally and comprehensibly from certain everyday abilities of perception, understanding, logic, memory, and thinking style. To this extent, Engineers have been prepared by training to be creative. They have a mindset that enables creativity to thrive. They have developed their abilities of perception, understanding, logic and thinking style to the extent that they can be very creative as their products all over the world testify. Leadership can be very effective when it is incorporated with creative changes that will advance the society in this changing world.

The personal characteristics of creative leaders are that they must be intelligent, ${ }^{[22]}$ and it is no doubt that Engineers are naturally intelligent. In fact, the success of engineering is based on a deep reservoir of talented people. Creative leaders should be well informed technologically; they require this information especially now that the world is driven by technology. This will enable them to know the limits where creative thoughts will be most fruitful. It is worthy to note that when creative leaders are shown ideas. They are not too quick to judge or reject the idea, but think carefully what they are looking for, ask the right questions in the most effective way, to clarify the reasons for their acceptance or rejection of the emerging ideas. Similarly, the engineering mindset tends to focus on the long term. For instance, when you build a bridge that will be there for decades to come, you do not have to think only about its ability to meet the design specifications and objectives at the present, but also on its ability to absorb future increasing traffic. 


\section{Conclusion}

The critical nature of this paper, "Beyond Professionalism: Can a Good Engineer make a Good Leader?" will not only change the opinion of others towards Engineers but more importantly, will shake off the mindset which Engineers have been living with, starting from his days as an engineering student. Engineering has been a scapegoat of our times when compared with other professions. The engineer is said to be deficient in training for culture and humanities. The, journalists, lawyers, political scientists, doctors, scientists etc. are never criticized the same way. In discussing about education, it is the engineer that is criticized for not having adequate humanities in his curriculum. The serious inadequacies of other professions are not evaluated in the same manner. While accepting the fact that Engineers are not all rounder, so also goes with other professions.

A country can be a place where power failure does not occur and means of transportation is expanded to meet the traveling/haulage needs of the people, where infrastructural facilities are accomplished on budgeted schedule and innovation and creativity are the order of the day, where healthcare is made very affordable and corruption is reduced to its barest minimum. Where do you think that country will be developmentally? Your guess is as good as mine. It is a country in which Engineers are made the political leaders and very active in public policy decisions.

\section{References}

[1] Saviour Robert (2005). The Engineer Personality [Online] Available: www.seviourbooks .com/articles/ engineer (July 7, 2012)

[2] Pinto Jim 2007, Engineers can be Leaders [Online] Available: www.isa.org/ intechtemplate.cfm (February 12, 2011)

[3] Hawley, Robert (2001). Were you born to lead? Engineering Management Journal, London: The Institution of Engineering and Technology. pp. 247-8

[4] Jon Pinto 2011 The Art of Engineering Leadership http://www.automation.com/sitepages/ pid1649.php accessed on 13th February, 2011

[5] Kolla D. T. (1981). The Engineer Image The Search Quarterly Magazine, Accra.

[6] Vinto M. (2001), The Nature and Engineering Engineering Discovery Newsletter, Makitt, VC, pp 23-45

[7] Frederick P. Brooks (1995). The Mythical Man-Month: Essays on Software Engineering, University of North Carolina at Chapel Hill, 2nd ed., pub. Addison-Wesley

[8] Roger Revelle (1987). The Scientist and the Politician in Societal Issue, Scientific View Points Margaret Strom Ed. American Institute of Physics.

[9] Batchelder N. (2010). Engineers as Leaders http://nedbatchelder.com/blog/201010/ engineers_as_leaders.html accessed on 10 March, 2011.

[10]Langdon Winner (1976). Engineering Ethics and Political Imagination in Paul T. Durbin (ed.). Broad and Narrow Interpretations of Philosophy of Technology. 53 - 64, Netherlands, Kluwer Academic Publishers, 53 - 64.

[11] Johnston, S., Gostelow, J.P., and W.J. King. (2000). Engineering and Society. New York: Prentice Hall

[12] Robert, Boguslaw (1965) The New utopians: A Study of Systems Design and Social Change Englewood Cliffs, N. J. Prentice-Hall, 1965

[13]Langdon, Winner (1986) Engineering Ethics and Political Imagination

[14] Momah, Sam (1999). Technology is Power Mufadenic Press Limited, Lagos

[15] David Billington D. (1996). The Innovators: The Engineering Pioneers Who Made America Modern New York: John Wiley \& Sons 
[16]Loui, Michael (1992). Engineering, Politics and Government. A Speech at the Eta Kappa $\mathrm{Nu}$ Initiation Ceremony on November 13, 1992

[17] Colhoun, J. C. (1964). The Engineer and Society, National Academic Press, Washington

[18] Moriarty, G. (2008). The Engineering Project : Its Nature, Ethics and Promise, The Pennsylvania State University Press, Pennsylvania

[19] Okonkwo, U. C. (2012). The Engineer: Professionalism in Society. Awka: SCOA Heritage Systems.

[20] Florman S. (1987). The civilized engineer. New York: St. Martin's Press

[21] Perkins, D. N. (1981). The Mind's Best Work (Cambridge, Mass.: Harvard University Press

[22] Arieti, S. (1976). Creativity: The Magic Synthesis New York: Basic Book 